\title{
A produção da (des)informação sobre violência: análise de uma prática discriminatória
}

\author{
Production of (mis)information on violence: \\ analysis of a discriminatory practice
}

Kathie Njaine 1

Edinilsa Ramos de Souza 1,2

Maria Cecília de Souza Minayo 1

Si mone Gonçal ves de Assis 1,2

\footnotetext{
1 Centro Latino-Americano de Estudos sobreViolência e Saúde "Jorge Carelli", Escola Nacional de Saúde Pública, Fundação Oswaldo Cruz. Av. Brasil 4036, sala 702, Manguinhos, Rio de Janeiro, RJ 21040-361, Brasil.

2 Departamento de Epidemiologia e Métodos Quantitativos em Saúde, Escola Nacional de Saúde Pública, Fundação Oswaldo Cruz. Rua Leopoldo Bulhões 1480, 80 andar, Rio de Janeiro, RJ 21041-210, Brasil.
}

Abstract We propose a critical reflection on quality of information concerning violence in Brazil, emphasizing some of the main sources of primary data: Public Law Enforcement Departments, Police, and Municipal and State Secretaries of Health. The city of Rio de Janeiro is taken as a typical "case" in this analysi s. The hypotheses are: (a) in the process of producing this information, its generation, systematization, and dissemination are poor quality, thus becoming banal and revealing their discriminatory bias; (b) data are treated as private tools and not as a public service, thus reflecting an authoritarian and bureaucratic institutional structure. They themsel ves become a form of (mis)information, void of any valid social or political meaning and insufficient to inform society about the real expression of violence and to aid in formulating effective public policies. Conclusions are as foll ows: 1) that information on violent events bevalued from the time it is recorded until it is put to social use: 2) that professionals and institutions dealing with the issue transform structures and ideas with a view towards an integrated and conscious fulfillment of their social roles; and 3) that soci ety organize and work collectively against violence, bolstering the value of human life.

Key words Information; Violence; Public Health; Quality of Registries

Resumo No presente artigo, realiza-se uma reflexão crítica da qualidade da informação sobre vi olência no Brasil, destacando-se al gumas das principais fontes primárias de dados: as Secretarias de Segurança Pública e de Polícia Civil e as Secretarias Municipais e Estaduais de Saúde. O Muni cípio do Rio de Janei ro é abordado como um "caso" exemplar nesta análise. Parte-se das hipóteses de que: (a) no processo de produção dessa informação, a geração, sistematização e divulgação são de má qualidade, banalizadas, espetacularizadas e discriminatórias; (b) os dados são tratados como instrumento de domínio privado e não como uma prestação de serviço ao público e refletem uma estrutura institucional autoritária e burocratizada. Constituem-se em (des)informações esvaziadas de si gni ficado sóci o-político, insufici entes para informar à soci edade sobre a real expressão da violência e para a formulação de políticas públicas. Como conclusão, destaca-se a necessi dade de que: 1) as informações sobre os eventos vi ol entos sej am val orizadas desde o seu registro até o seu uso social; 2) os profissi onais e as institui ções envolvidas com o tema transformem estruturas e mentali dades no senti do de uma ação integrada e consciente do seu papel social; 3) a sociedade se organize e atue em conjunto contra a violência e pel a valorização da vida humana.

Palavras-chave Informação; Violência; Saúde Pública; Qualidade de Registro 


\section{Introdução}

As fontes oficiais de informação sobre violência no Brasil, dentre as quais encontram-se as Secretarias de Segurança Pública e as Secretarias Municipais e Estaduais de Saúde, indicam que este fenômeno tem crescido, especialmente nas áreas urbanas de suas grandes metrópoles. Com base nos dados daquelas primeiras são sistematizados os crimes e delitos enquadrados pelo Código Penal, enquanto às Instituições de Saúde cabe informar sobre a morbidade e a mortalidade por causas externas (esta última constitui um grupo da Classificação Internacional de Doenças/CID, sob os códigos E800 a E999 da nona revisão, que engl oba todos os acidentes, os suicídios e os homicídios).

Valendo-se dos dados policiais, é possível identificar que a grande maioria dos crimes é cometida contra a propriedade privada. A análise feita por Teixeira (1994) em relação ao censo penitenciário do Rio de Janeiro, em 1988, revela que $62 \%$ da população carcerária estavam condenados por esses crimes; só $11 \%$ das condenações eram por crimes contra a vida (homicídios e lesões corporais).

No âmbito da Saúde Pública, o conhecimento que se tem é de que, na década de 80 , a violência mudou o perfil de mortalidade do país, passando de quarta para segunda causa de morte, perdendo apenas para as doenças cardiovasculares. Os acidentes de trânsito e a crescente freqüência dos homicídios foram os responsáveis pela maior magnitude e impacto desse grupo de mortes em relação às demais causas.

Sabe-se, entretanto, que uma gama significativa dessas formas de violência não chega ao conhecimento institucional oficial, constituindo uma cifra 'negra', sobre a qual não há quaisquer informações. Além disso, outras tantas formas de violência não são sequer reconhecidas pela sociedade e, conseqüentemente, por suas instituições, como é o caso de certas expressões de violência contra crianças, adolescentes e mulheres, que permanecem invisíveis. Mesmo o que é registrado padece de sérias limitações, tendo em vista o mal preenchimento dos formulários que deixam de informar dados essenciais ao esclarecimento dos eventos, o que tem implicações na resolução dos casos e punição dos agressores.

É com base nestas constatações que se pretende desenvolver a presente reflexão crítica acerca da informação sobre violência no Brasil, buscando-se discutir suas peculiaridades, desde a geração até o significado e utilização nos meios científico, político e social. Procura-se destacar a relevância deste processo de produ- ção da informação no contexto geral do País, cujo impacto na morbi-mortalidade pretensamente deveria mobilizar um sentimento de indignação e ensejar movimentos de transformação dessa realidade no sentido de val orização da vida.

Para este objetivo, considera-se como violência os eventos fatais e não fatais decorrentes de todos os tipos de acidentes, bem como aqueles provenientes de violência intencional (agressões, homicídios, suicídios e suas tentativas).

\section{Os paradoxos da informação no mundo moderno}

Um dos aspectos que caracterizam a segunda metade do século XX é a implantação de uma rede planetária de telecomunicações e de informações. Segundo a tendência mundial de globalização, uma grande parte da população do planeta recebe diariamente notícias de outras sociedades, e essa noção do global, ainda que incipiente e caricata, passa a ser incorporada à cultura. Por outra parte, milhões de indivíduos que se integram em redes de informática se correspondem, criando, assim, uma nova noção de integração e comunicabilidade.

Vários autores, dentre os estudiosos brasileiros, têm analisado o impacto dessas mudanças que, de um lado, englobam as totalidades, diminuem as distâncias e dão novo ritmo ao tempo e, de outro, criam infinitas possibilidades de proliferação de fontes de informação, ampliando o domínio de alguns, dialetizando e reinterpretando o que é produzido (Rondelli, 1995; Fausto Neto, 1995; Pitta, 1995). Outros como Njaine (1994) e Ribeiro \& Souza (1995) buscam enfrentar o desafio de refletir sobre o uso social da informação.

Uma das questões que se levanta é o mito da democratização: existe um pressuposto de que, uma vez informatizados, os dados são de livre acesso ao usuário que saiba acessá-los. No entanto, a verdade é que o acúmulo de conhecimento em algumas áreas científicas, tecnológicas e de interesse dos cidadãos ou não está acessível, ou pertence ao mundo hermético dos entendidos, deixando em total desinformação parcelas majoritárias da população. Por sua vez, temas de caráter público chegam ao conhecimento dessa população, privatizados pelos interesses dos meios de comunicação e dos financiadores, quando não são espetacularizados pela tendência ontológica da mídia de transformar o que for possível em entretenimento, novidade e sensação. 
No caso específico da violência, a ser tratado aqui, o processo de produção da informação, por um lado, não reflete a realidade e a intensidade dos eventos que deveria recobrir; por outro, adequa-se à concepção dominante de violência e de sujeitos violentos que a sociedade hegemonicamente retém em seu imaginário, realizando uma crítica sobre essa criação simbólica. Destas constatações advém o principal objetivo deste trabalho, que é o de refletir criticamente sobre essa criação simbólica.

Esse processo de produção, tomado exemplarmente do caso Rio de Janeiro, reúne na sua origem um conjunto de instituições públicas, tais como as Secretarias de Segurança Pública e a Estadual e Municipal de Saúde, além de outras instituições governamentais e não governamentais, alimentando as estatísticas científicas dos grupos de pesquisa e o noticiário ‘informativo' das 'multimídias'.

As hipóteses iniciais, que poderão ser confirmadas através dos dados aqui apresentados, são de que:

1) no nível da geração de informações:

a) constata-se uma precária formação dos profissionais que lidam com os registros e uma desconexão dessa tarefa com o fluxo geral da informação;

b) existe uma desvalorização cultural do registro nas instituições públicas;

c) essa desvalorização está relacionada ao estigma social criado em torno da parcela preponderante das vítimas de violência, que são pobres, negros e residem nas periferias urbanas.

2) no nível da divulgação dessas informações: a) do ponto de vista científico, existe uma insati sfação em relação à insuficiência desses dados, buscando-se por artifícios técnicos minimizar as deficiências destes nas fontes primárias;

b) do ponto de vista da mídia, a maioria das informações sobre violência é acolhida acriticamente, como tema de notícias e matérias curiosas, de disfunção social, cotidianamente transformada em relatos jornalísticos sensacional istas, por suas características potencialmente dramáticas e aterrorizantes. Ela é transmitida dentro de uma ótica de “informação espetáculo". Desta forma, ressaltam-se fatos violentos relativos à morte, ao acidente ou ao agravo de pessoas notórias do mundo político, dos negócios e artístico. Permanece, porém, quase ignorada, quando se trata dos párias, excluídos e presos, categorias sociais sem rosto e sem nome, passíveis de ser eliminados, uma vez que são considerados economicamente desnecessários e inviáveis, politicamente incô- modos e socialmente inoportunos, como bem expressam Cruz Neto \& Minayo (1994). Concomitantemente à exclusão sócio-política, econômica e cultural, incide sobre eles também a "exclusão moral", nas palavras de Pinheiro (1995). A imprensa escrita, sobretudo aquela que, segundo o dito popular, "se espremer sai sangue", utiliza-se dessa exclusão social para dissecar os corpos, compondo histórias patéticas, mostrando o insólito e o monstruoso, seja dos autores, seja das vítimas da violência.

\section{Fontes de informação dos eventos violentos}

As informações sobre violência são geradas por diversas fontes, conforme pode ser visualizado no organograma (Figura 1).

\section{Organograma}

Cada uma dessas instituições tem atribuições, obj etivos e funções sociais distintas e suas atividades envolvem diferentes níveis de complexidade, exigindo conhecimento e técnicas específicas. Na prática, contudo, percebe-se que organizam-se como estruturas fortemente burocratizadas, submersas em uma rotina arcaica e culturalmente autoritária, em que a tarefa de informar é deslocada de sua função social, não sendo, portanto, considerada importante. A esse respeito Sodré (1992) refere-se, citando Maffesoli, ao identificar a existência de um tipo de violência invisível, que é a violência institucional, ou seja, a violência dos órgãos burocráticos, dos estados e do serviço público. Trata-se de instituições cuja cultura informacional constitui-se, ela mesma, numa prática violenta, à medida em que esvazia o sentido e o significado da informação, não contribuindo para qualquer mudança social.

\section{Produzindo a (des)informação sobre violência}

Nesta fase de geração, observa-se que o evento violento é pouco esclarecido, tanto por parte da polícia, quanto dos serviços de saúde. A ausência, em ambas as instituições, de dados necessários para o esclarecimento dos eventos reflete diretamente nos formulários, que são mal preenchidos não só pela precariedade da investigação (muitas vezes prejudicada pelo envolvimento de algum policial com o crime), como também por desinteresse e descaso. Contribuem ainda para a má qualidade dos re- 


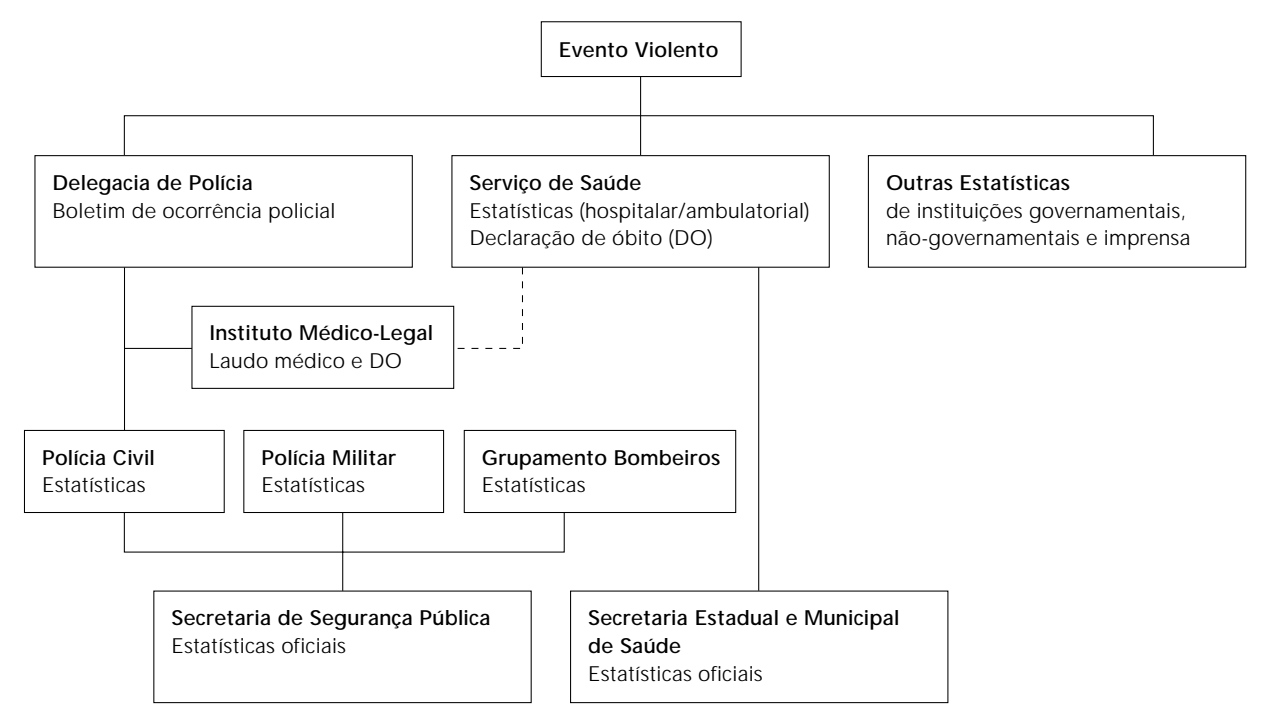

* O presente organograma representa o fluxo da informação no Estado do Rio de J aneiro. Em outros Estados do país o fluxo pode assumir características diferentes.

gistros as péssimas condições de trabalho e o despreparo dos profissionais com relação à importância da própria atividade que realizam.

Estas afirmações podem ser mais bem visualizadas nas Tabelas 1 e 2, onde estão listadas as proporções de 'informação ignorada' e 'sem informação' de alguns campos dos boletins de ocorrência policial e da declaração de óbito, respectivamente. De acordo com estas tabelas, observam-se el evadas proporções de informações não esclareci das em relação a certas variáveis fundamentais para a elucidação adequada do evento violento.

Como se pode observar nestas duas tabelas, tanto nas informações oficiais da Polícia, quanto nas da Secretaria de Saúde, a qualidade em relação a al guns dados essenciais é extremamente precária, contribuindo para a obscuridade e impunidade dos crimes cometidos, no caso dos registros policiais, e para a distorção da realidade, no que se refere às estatísticas da Secretaria de Saúde que vão al imentar o Sistema de Informação sobre Mortalidade do Ministério da Saúde.

Essa situação vem reforçar a hipótese inicial de que não é importante identificar nem o agressor nem a vítima, na medida em que suas vidas valem pouco (ou nada), que esses papéis podem ser intercambiáveis, e que esse evento fatal não redundará em nenhuma justiça ou em nenhuma indignação da sociedade. Quase sempre, por falta de provas, arquivam-se inves- tigações que nem chegam a processos judiciais. Em uma entrevista do titular da Segunda Vara da Infância e Juventude, o Juiz Geral do Prado afirmou que mil menores morreram de forma violenta no Rio, entre janeiro e outubro de 1995 . Destes, $60 \%$ foram assassinados, enquanto $40 \%$ foram vítimas do trânsito e dos chamados 'autos de resistência', ou seja, foram mortos sob a alegação de que enfrentaram a polícia a tiros. O juiz comenta que apenas 3\% desses jovens tinham sido processados judicialmente (Jornal do Brasil, 1996a). Em recente pesquisa realizada pelo Instituto Fernandes $\mathrm{Fi}$ gueira, da Fundação Oswaldo Cruz, com base nos boletins de ocorrência policial do Rio de Janeiro, apurou-se que, dos 106 casos de violência contra crianças de zero a cinco anos de idade ocorridos em 1990, em apenas 24 foram instaurados inquéritos. Destes, somente um caso foi concluído, indo a julgamento e o agressor sendo absolvido.

No caso específico das Secretarias de Saúde, que coletam os dados preenchidos na declaração de óbito pelo Instituto M édico Legal (IML), a insuficiência de informação reflete diretamente na elucidação da causa básica do óbito. O não-preenchimento do campo próprio na declaração de óbito sobre o tipo de violência ocorrida pode ser observado na Tabela 2, onde se vê que $53,2 \%$ dessa variável constam como sem informação ou a informação é ignorada. Outro fator fundamental é a falta de es- 
clarecimento sobre as circunstâncias que levaram à morte. $\mathrm{O} I \mathrm{ML}$, que por lei deve atestar todos os óbitos por causas externas, informa apenas a lesão que provocou a morte sem esclarecer o grupo de causa externa no qual essa lesão pode ser classificada (se a lesão ocorreu por causa de um acidente, por um suicídio ou por um homicídio). Em algumas capitais brasileiras essa dificuldade de esclarecimento é mais gritante, como é o caso do Rio de Janeiro. Nesta cidade, quase metade das mortes por causas externas são classificadas pela Secretaria de Saúde no grupo das lesões que se ignora se acidental ou intencionalmente infligidas (códigos E980-E989 da Classificação Internacional de Doenças/CID), porque não se consegue saber de que decorreram. Vale ressaltar que a grande maioria dos óbitos que compõem esse grupo de mortes por causas externas, inadequadamente classificadas neste grupo inespecífico, envolve o uso de armas de fogo. Fica claro que muitos homicídios acabam inseridos nessa categoria e não no grupo dos homicídios propriamente ditos, levando à subestimação desta causa. Essas distorções podem ser vistas naTabela 3.

De acordo com a Tabela 3, pode-se constatar que são elevadas e crescentes as proporções de mortes por causas externas classificadas como lesão ignorada, chegando a representar $69 \%$, em 1992, e $60 \%$, em 1994, do total das causas externas. Por outro lado, percebe-se que o grupo das lesões ignoradas por arma de fogo representa, entre 1985 e 1993, mais da metade de todas as lesões ignoradas. Em função dessa distorcida classificação, os percentuais de homicídios ficam subestimados, uma vez que se sabe por meio de outros estudos (Souza, 1994) que a grande maioria dos homicídios são perpetrados por arma de fogo e que grande parcela das lesões ignoradas com a utilização desse instrumento tem características típicas de homicídios (Souza, 1991). Essa autora, estudando a mortalidade em Duque de Caxias, encontrou que os homicídios informados na declaração de óbito eram cerca de três vezes menos freqüentes do que nos boletins de ocorrência policial . Grande parte dos homicídios informados pela polícia estavam classificados como lesões ignoradas por arma de fogo na declaração de óbito.

Uma outra forma de identificar falhas na geração dos dados foi observada por Souza \& Freitas (1995). Esses autores, analisando os homicídios de adolescentes de 15 a 19 anos, informados pela Secretaria de Polícia Civil do Estado do Rio de Janeiro, no ano de 1990, encontraram que cerca de $67 \%$ desses crimes não tinham esclarecidas as circunstâncias em que
Tabela 1

Proporção de variáveis sem informação e informação ignorada segundo boletins de ocorrência policial*.

\begin{tabular}{lc}
\hline $\begin{array}{l}\text { Variáveis** } \\
(\mathrm{n}=9.204)\end{array}$ & $\begin{array}{c}\text { Sem informação }+ \\
\text { Informação ignorada (\%) }\end{array}$ \\
\hline Sexo da vítima & 0,3 \\
Idade da vítima & 3,2 \\
Hora da ocorrência & 0,3 \\
Instrumento utilizado & 15,2 \\
Identificação do agressor & 57,7 \\
Comunicante do fato & 5,8 \\
Realização de exame & 83,9 \\
Existência de testemunha & 12,4 \\
Local de ocorrência do fato & 5,7 \\
Sexo do agressor & 35,5 \\
Relação do agressor com a vítima & 55,3 \\
Local do ferimento & 48,8 \\
\hline
\end{tabular}

* Dados referentes à população de zero a 19 anos do Município do Rio de J aneiro, no ano de 1990.

** Incluem registros fatais e não fatais da Secretaria de Estado de Polícia Civil do Rio de Janeiro.

Tabela 2

Proporção de variáveis sem informação e informação ignorada segundo declarações de óbito*.

\begin{tabular}{lc}
\hline $\begin{array}{l}\text { Variáveis } \\
\text { ( } \mathrm{n}=5.095)\end{array}$ & $\begin{array}{c}\text { Sem informação }+ \\
\text { Informação ignorada (\%) }\end{array}$ \\
\hline Sexo da vítima & 0,2 \\
Estado civil da vítima & 10,7 \\
Local de ocorrência do óbito & 1,6 \\
Ocupação da vítima & 74,6 \\
Naturalidade da vítima & 11,5 \\
Instrução da vítima & 31,9 \\
Assistência médica & 35,2 \\
Instituição atestante & 14,3 \\
Necropsia & 32,2 \\
Local do acidente & 60,6 \\
Tipo de violência & 53,2 \\
\hline
\end{tabular}

Fonte: Secretaria Estadual de Saúde do Rio de J aneiro.

* Dados referentes à mortalidade na faixa de zero a 19 anos no Município do Rio de Janeiro, no ano de 1993.

foram perpetrados, constando como homicídios sem quaisquer informações sobre as causas que os motivaram, sem nenhuma identificação do agressor e sem nenhuma testemunha. Para essas mortes, no local onde deveria ser feito o relato do fato, preenche-se simplesmente 'sem informação'.

Sabe-se que essa carência de informação advém, em parte, da dificuldade da polícia em conseguir obter algum depoimento da popula- 
Tabela 3

Mortalidade por causas externas e subgrupos específicos*.

\begin{tabular}{|c|c|c|c|c|c|c|c|}
\hline \multirow[t]{2}{*}{ Ano } & \multirow{2}{*}{$\begin{array}{c}\text { Externas } \\
\text { (E800-E999) } \\
n\end{array}$} & \multicolumn{2}{|c|}{$\begin{array}{l}\text { Homicídios } \\
\text { (E960-E969)** }\end{array}$} & \multicolumn{2}{|c|}{$\begin{array}{l}\text { Lesões ignoradas } \\
\text { (E980-E989)** }\end{array}$} & \multicolumn{2}{|c|}{$\begin{array}{l}\text { Lesões ignoradas por } \\
\text { arma de fogo (E985)*** }\end{array}$} \\
\hline & & $n$ & $\%$ & $n$ & $\%$ & $\mathrm{n}$ & $\%$ \\
\hline 1980 & 943 & 276 & 29,3 & 299 & 31,7 & 13 & 4,3 \\
\hline 1985 & 954 & 78 & 8,2 & 444 & 46,5 & 301 & 67,8 \\
\hline 1990 & 1.310 & 615 & 46,9 & 162 & 12,4 & 93 & 57,4 \\
\hline 1991 & 1.203 & 328 & 27,3 & 554 & 46,1 & 326 & 58,8 \\
\hline 1992 & 1.070 & 162 & 15,1 & 738 & 69,0 & 427 & 57,9 \\
\hline 1993 & 1.172 & 288 & 24,6 & 624 & 53,2 & 340 & 54,5 \\
\hline 1994 & 1.271 & 313 & 24,6 & 762 & 60,0 & 321 & 42,1 \\
\hline
\end{tabular}

Fonte: Secretaria Estadual de Saúde do Rio de J aneiro.

* Dados referentes à mortalidade na faixa de zero a 19 anos no Município do Rio J aneiro.

** Percentuais calculados em relação às causas externas.

*** O grupo das lesões ignoradas por arma de fogo faz parte do grupo das lesões ignoradas, portanto seus percentuais foram calculados em relação às lesões ignoradas.

ção, que muitas vezes testemunha o ocorrido, mas silencia por medo. É a chamada lei do silêncio. O medo é manifestado tanto em relação à polícia, quanto à ameaça representada pelo dito bandido ou grupo do crime organizado que domina o local.

A (des)informação também é fruto do acobertamento de mortes provocadas pelo confronto com policiais. É, no mínimo, contraditório notar que, numa análise da série histórica de 15 anos (1980 a 1994) sobre a mortalidade de crianças e adolescentes do Rio de Janeiro, nenhum óbito decorrente dessa circunstância foi registrado (Souza et al., 1996), quando a mídia diariamente noticia vítimas fatais em tiroteios com a polícia. Em reportagem do Jornal do Brasil, de 7 de abril (1996b), destacam-se o crescimento de mortes de civis por policiais militares, a não-identificação de cerca de metade das vítimas e de suas características pessoais e as falsas noções de que essas pessoas estão sendo mortas por serem supostos criminosos, resistirem à prisão e encontrarem-se fortemente armadas.

Toda essa problemática, que produz informação de má qualidade, também provém de distintos entendimentos quanto à causa da morte. Para o IML, esclarecer a circunstância em que ela ocorreu significa determinar a causa jurídica do óbito. Isto não pode, ou não deve ser feito, antes das devidas investigações, uma vez que a declaração de óbito pode vir a ser usada como prova de inquérito com as devidas implicações legais para o agressor. Já para a Secretaria de Saúde, interessa identificar a causa básica que provocou a morte daquela vítima, a fim de compor as estatísticas de mortalidade do País.
Com o objetivo de conciliar esses distintos entendimentos, o Ministério da Saúde acrescentou à declaração de óbito uma advertência de que a informação serve apenas para fins epidemiológicos, não se prestando, portanto, para finalidades legais. Essa tentativa não foi ainda devidamente avaliada, de modo que se desconhece sua efetividade. Sabe-se que, em certas capitais, como é o caso do Rio de Janeiro, existe uma resistência por parte do IML em adotar essa nova concepção.

As especificidades de cada uma dessas instituições quanto ao registro e classificação dos fatos, que se associam às lógicas de funcionamento das mesmas, não encerram por aí. A utilização de diferentes termos para designar um mesmo fato é um outro complicador da informação que provém do uso de diferentes classificações. Enquanto as Secretarias de Saúde adotam a Classificação Internacional de Doenças, recomendada pela Organização Mundial de Saúde, a Polícia utiliza os termos do Código Penal. Desse modo, como exemplo, o que para o Setor Saúde é um acidente de trânsito, para a Segurança Pública é um homicídio culposo.

Embora existam questões técnicas aventadas como desculpas para deficiências na prestação de informações, as práticas culturais dos profissionais da Segurança Pública e do Setor Saúde também reforçam e são reforçadas pelos estigmas que designam as vítimas da violência e acabam reproduzindo um tipo de informação preconceituosa e segregadora. Ao descreverem-nas, minimizam o fato, negligenciam ou mesmo se omitem em relação a certos casos que lhes chegam às mãos, ora porque 
não consideram que seja de sua alçada, ora porque imprimem às vítimas estereótipos que as relacionam a situações de marginalidade. Essa atitude dos profissionais acaba por descaracterizar o evento violento.

Em pesquisa realizada pelo Centro LatinoAmericano de Estudos sobre Violência e Saúde "Jorge Carelli" (Claves, 1995), verificou-se que a própria linguagem utilizada pelo policial para preencher os boletins varia em função da sua formação, da sua visão de mundo, mas, sobretudo, pela percepção que ele tem da clientela atendida, segundo os espaços sociais. Assim, para as crianças e adolescentes que sumiram de casa da Zona Sul da cidade do Rio de Janeiro, o registro é feito como um seqüestro, ao passo que, quando se trata de uma criança ou adolescente da Zona Norte, a queixa é registrada como um simples desaparecimento, indicando claramente uma classificação territorializada dos eventos.

Quanto aos casos que envolvem violência sexual, desde o exibicionismo até aqueles indicativos de estupro, costumam ser classificados pela Polícia como atentado ao pudor. Por outro lado, a lei que rege esses crimes apenas admite o estupro quando ocorre a penetração vaginal . Nos casos de penetração anal ou outras formas menos graves de abuso sexual, considera indiferentemente como um atentado violento ao pudor, cuja penalidade é a mesma do estupro (de seis a dez anos de prisão). Nos casos em que o estupro é qualificado (provoca lesões corporais graves), o crime passa a ser considerado hediondo e a pena sobe para o prazo de oito a 12 anos. Dados de Assis \& Souza (1995) mostram que, em $35 \%$ das crianças e adolescentes do Rio de Janeiro vítimas de abuso sexual, não foi efetuado nenhum tipo de exame pericial para investigar a veracidade do fato. Com relação aos agentes de saúde, observa-se uma percepção seletiva por parte destes, a qual tende a destacar a violência sexual em detrimento de outras formas mais freqüentes de violência, como a física e a psicológica. Além disso, de modo geral, as vítimas de violência sexual sofrem um tratamento discriminatório por parte das instituições que, supostamente, deveriam prestar-Ihes assistência, agravando ainda mais o sofrimento destas.

Numa análise de dois processos do conhecido extermínio de Acari, pesquisadores do Claves puderam percorrer a construção policial do inquérito, no qual observaram: (a) a transformação das vítimas em culpadas, distorcendo os depoimentos de testemunhas nos inquéritos; ( $b$ ) a diferença entre os depoimentos dos familiares, que tendem a humanizar as vítimas, e o discurso dos policiais, que aprofunda insistentemente estereótipos, apelidos depreciativos e a culpa social dos mortos.

\section{O processamento dos registros sobre violência}

Oficialmente, as instituições têm a responsabilidade de fornecer as informações sobre os eventos violentos, embora suas atribuições extrapolem essa função. O que se observa, entretanto, é que estas informações são desqualificadas, perdendo-se de vista o seu potencial analítico. Dos registros (boletins de ocorrência e declaração de óbito), muito pouco se acaba sabendo (e o que se sabe reflete todas as distorções já referidas). As estatísticas oficiais, quando muito, informam apenas a distribuição da violência segundo tipo, sexo e faixa etária, descaracterizando-se, dessa forma, grande parte dos atributos das vítimas e das circunstâncias do evento.

Trata-se, portanto, de registros para os quais maior detalhamento e refinamento de certos dados só são possíveis quando o próprio interessado (usuário) se dispõe a efetuá-los.

De modo geral, as informações por parte de quem as processa, como os Ministérios da Saúde e da Justiça e as Secretarias de Saúde, são defasadas, às vezes em anos, como é o caso das estatísticas de mortalidade, impedindo qualquer tomada rápida de ação.

Após geradas e processadas por cada instituição, o resultado é desalentador. A informação é inconsistente, cada instituição refere diferentes montantes para um mesmo evento e acaba-se sem saber ao certo, por exemplo, dados básicos como quantos acidentes de trânsito ou quantos homicídios ocorreram no período de interesse. Isso sem contar outros dados decisivos para a formulação de políticas públicas em geral.

Baseadas em informações tão precárias, as ações de segurança pública, assim como as do setor saúde, acabam prejudicadas. A Polícia alega que não tem elementos suficientes para investigar; a Justiça não pune porque a investigação policial não fornece as evidências e provas necessárias; o serviço de saúde não detecta os casos e, quando o faz, não encaminha ou não sabe que atitude adotar, ou, ainda, prefere ignorar seu compromisso e age negligentemente em relação à violência. Em resumo, a sociedade, ora desconhece a magnitude e o significado de seu processo de violência, ora se contenta com o que lhe é oferecido como sendo a verdade. 
Quaisquer políticas públicas calcadas em informações que sequer servem para direcionar as próprias ações das instituições nas quais são geradas tornam-se inviáveis ou inoperantes, porque antes de qual quer coisa, caracterizam-se como um falso dado da realidade, cuja expressão social e política reproduz o "status quo" e reforça as discriminações.

A divulgação de informações sobre violência através da mídia

A informação assume a forma e a importância que lhe é dada pela sociedade. No caso da violência, percebe-se que o grupo social mais vitimizado é aquele social mente excluído da festa do consumo, desprovido dos símbolos que caracterizam o 'cidadão de bem', revestido pelos signos da pobreza, como ser jovem, negro e morar em morro ou periferia da cidade, sendo identificado como bandido. O fato de ser adolescente ou adulto jovem, dos 15 aos 24 anos, do sexo masculino, também representa risco para esse grupo social, conforme destacam Minayo \& Souza (1993). Para estes, a sociedade não se importa em esclarecer a morte, porque no imaginário social essas mortes representam uma espécie de 'limpeza' e de solução para o problema da violência e das questões sociais e econômicas do País. Suas vidas são sentenciadas sumariamente (Cruz Neto \& Minayo, 1994). Assim, a 'culpa' socialmente construída e atribuída a esta parcela da sociedade, que passa a preencher a função de bode expiatório, impede que esta mesma sociedade tome conhecimento e responsabilize outros membros, de estratos sociais mais privilegiados, envolvidos em seus processos de criminalidade.

Cabe à mídia uma destacada contribuição na desqualificação das informações sobre violência, pois essa ocupa na sociedade contemporânea um papel importante como mediadora social, como agente de socialização, ao lado da família, da escola e de outras instituições (Rey, 1993). Desse modo, a tel evisão e demais meios de comunicação são instrumentos, dispositivos culturais e sociais. Quando nesses meios circulam informações sobre o tema violência, é de forma banalizada, gerando muitas vezes um clima de pânico e medo na sociedade. Assim, socializa-se um modo de ver e de interpretar o fenômeno, que distorce a realidade, hipertrofia os fatos através da espetacularização da notícia e da estética das imagens, desvia o foco da atenção para o perigo imaginário que se restringe e localiza em certos tipos de sujeitos e nas camadas e espaços sociais menos fa- vorecidos. Ao gerar informações sobre violência, a mídia reproduz, de certo modo, o processo de transmissão dessas informações efetuado pelos órgãos oficiais do governo, onde o sentido dos diversos tipos de violência que ocorrem na sociedade e, principalmente da violência estrutural, é desfeito ou desrealizado, conforme trata Sodré (1992).

Na verdade, como revela Rondelli (1994/95), a mídia está muito mais voltada a entreter que a informar, tem seus próprios critérios de relevância, e, assim, o tema da violência pode ser politizado ou despolitizado em função do reforçamento e da ampliação dos estereótipos sociais.

Este texto, no entanto, não pretende tratar da relação de causa e efeito que associa a mídia à reprodução ou aumento da violência social, mas analisar a questão da qualidade da informação sobre violência nos espaços privilegiados que ela ocupa dentro de um quadro informacional mais amplo. E é exatamente por se situar nestes lugares na sociedade que a informação deve ser pensada como um elemento de mudança e de transformação social.

\section{Considerações finais}

A construção de uma sociedade menos violenta e mais democrática implica a participação de todos os seus setores e segmentos, uma maior consciência dos seus agentes sociais e ações solidárias, tanto no nível individual quanto institucional.

Nesse sentido, a informação assume grande importância quando surge como um direito da sociedade e não como um produto de uso privado de instituições, sejam elas científicas, burocráticas, administrativas ou de comunicação. Ela também tem o potencial, ao ser bem gerada, sistematizada e divulgada, de mediar os processos de conscientização de direitos, e de integração dos setores segmentados da sociedade, sobretudo através das redes que hoje se formam visando à cidadania, em contraposição ao uso apenas mercadológico.

Pelo que se constata a partir da presente análise, a informação sobre violência no País é desqualificada, conseqüência tanto do autoritarismo, quanto do preconceito exercido pelas instituições públicas, cuja cultura legitima e autoriza um controle sobre as informações. $\mathrm{O}$ serviço que essas instituições deveriam prestar aos usuários (o público) passa a ser uma tarefa mal realizada e sem nenhum critério de qualidade, uma vez que as informações são tratadas como instrumentos de domínio privado e não 
como uma prestação de serviços à sociedade, o que justificaria o papel público dessas instituições.

Colocam-se em questão os limites e as responsabilidades dos agentes institucionais, restritos ao cumprimento mínimo e mecanizado de seus deveres profissionais, sem vislumbrarem e sem se comprometerem com o significativo crescimento da violência e suas conseqüências, o que os torna também responsáveis pela desqualificação da informação. Isto se expressa paral elamente à atuação truculenta da polícia, que atira antes de prender para investigar a culpabilidade (Americas Watch, 1993). Do mesmo modo pode ser entendida a intolerância e o tratamento diferenciado dos profissionais de saúde em relação às vítimas de causas externas, sobretudo os baleados que chegam aos hospitais de emergência, além do despreparo técnico e do desinteresse para identificar, tratar e encaminhar os casos.

Em termos de propostas, entende-se que cada instituição deve empreender um esforço no sentido de melhorar suas condições de trabalho, capacitar seus profissionais oferecendo cursos de aperfeiçoamento na área, nos quais a compreensão e conscientização da importância do conceito de informação no processo democrático do País sejam incorporadas à sua prática. No caso específico dos policiais, é preciso pensar numa mudança de mentalidade institucional, a fim de que a arbitrariedade e o abuso de autoridade sejam práticas desestimuladas e não condecoradas como tem acontecido.

Em relação aos registros, ressalta-se a necessidade de que os mesmos passem a informar adequadamente quanto a: identificação do agressor; tipo de evento ocorrido; realização de exames; ocupação e instrução da vítima; local de ocorrência do evento. Para isto, torna-se imprescindível que as investigações policiais sejam imparciais e eficientes, ou seja, que cumpram o seu papel.

Outra questão importante é a definição das responsabilidades que cabem a cada instituição, porque na geração de informações há uma considerável perda cumulativa no fluxo desse processo, resultante do fato dessas instituições não desempenharem devidamente suas funções. Exemplo disto é o não-esclarecimento da causa básica do óbito pelo Instituto Médico Legal, prejudicando a qualidade das estatísticas de mortalidade sistematizadas nas Secretarias de Saúde.

A necessidade de melhorar a qualidade da informação não deve ser entendida apenas do ponto de vista técnico, mas sim como uma possibilidade de capacitar a sociedade a tomar decisões coerentes com os seus problemas, com vistas ao avanço da cidadania e da qualidade de vida.

Por outro lado, acredita-se que a prática democrática de enfrentamento da violência precisa ser respal dada por políticas públicas mais amplas de prevenção e de promoção da saúde - com a participação de setores organizados da sociedade, uma vez que se trata de um fenômeno que afeta a todos. É, no mínimo, contraditório e preocupante que, em uma sociedade que se proclama democrática, os Ministérios da Justiça e da Saúde não tenham ainda se unido para promover a implantação de um programa prioritário de combate à violência, no seu sentido mais amplo.

Nos últimos anos, observou-se o surgimento de associações e programas de defesa da cidadania, como a associação de parentes das vítimas de violência, o grupo das mães de Acari e da Cinelândia, a Casa da Paz, em Vigário Geral, o disque-denúncia implantado no Rio de Janeiro, dentre outros, que visam, sobretudo, a denúncia, apuração e resolução de casos de violências e de desaparecimentos. Esses movimentos organizados, por um lado, vêm suprir as lacunas deixadas pelas instituições públicas e, por outro, revelam que a sociedade está se organizando e se mobilizando contra a violência.

Outras experiências, como o programa Desepaz - Desarrollo, Seguridad y Paz (Guerrero, 1995), implantado em Cali, Colômbia, têm mostrado resultados positivos, revertendo tendências ascendentes dos indicadores de violência. Este programa de controle e prevenção busca um trabalho conjunto de setores e instituições sociais, no sentido de melhorar a qualidade da ação e da informação, tornando-as coerentes e compatíveis entre as várias instituições notificadoras, e de atuação integrada visando a medidas preventivas.

Esta noção de Rede que o próprio tema suscita também vem sofrendo tentativas de ser incorporada em algumas capitais do Brasil. Este é o caso de Recife, cujas instituições governamentais e não governamentais estão desenvolvendo um trabalho neste sentido. Os efeitos deste esforço estão se refletindo na diminuição da mortalidade por acidentes de trânsito naquela cidade e também no caso exemplar do decréscimo em $30 \%$ dos homicídios no último carnaval. No Rio de Janeiro, a mesma abordagem vem aos poucos sendo proposta, principalmente pelo setor saúde, que tem desenvolvido medidas cujo objetivo é, em primeira instância, melhorar e agilizar a informação. Esses 
últimos exemplos, aparentemente simples, mostram que, de onde quer que se parta para atuar no campo da informação a fim de modificar o quadro da violência, pode-se obter algum resultado que venha contribuir positivamente para melhorar o serviço público, valorizar os técnicos e, sobretudo, valorizar a vida.

\section{Referências}

AMERICASWATCH, 1993. Violência Policial Urbana no Brasil: Mortes e Tortura pela Polícia em São Paulo eno Rio de Janeiro nos Últimos Cinco Anos, 1987-1992. São Paulo: Núcleo de Estudos da Violência/Universidade de São Paulo. Relatório de Pesquisa.

ASSIS, S. G. \& SOUZA, E. R., 1995. Morbidade por violência em crianças e adolescentes do Município do Rio de Janeiro. Jornal de Pediatria, 71:303-312.

CLAVES (Centro Latino-Americano de Estudos Sobre Violência e Saúde "Jorge Carelli"), 1995. Estudo Sócio-Epidemiológico da Morbi-Mortalidade de Crianças e Adol escentes Vítimas da Violência, no Município do Rio de Janeiro ena Baixada Fluminense. Rio de Janeiro: Claves/ENSP/Fiocruz. Relatório de Pesquisa. (mimeo.)

CRUZ NETO, O. \& MINAYO, M. C. S., 1994. Extermínio: violentação e banalização da vida. Cadernos de Saúde Pública, 10 (supl.I):177-187.

FAUSTO NETO, A., 1995. Percepções acerca dos campos da saúde e da comunicação. In: Saúde \& Comunicação: Visibilidades e Silêncios (A. M. R. Pitta, org.), pp. 267-293, São Paulo: Hucitec-Abrasco.

GUERRERO, R., 1995. Programa Desepaz (Desarrollo, Seguridad y Paz: Epidemiologia dela Violencia). Washington. (mimeo.)

JORNAL DO BRASIL, 1996b. PM mata cada vez mais. Jornal do Brasil, 7 de abril:27.

JORNAL DO BRASIL, 1996a. PMs são acusados de matar criança. Jornal do Brasil, 17 de abril: 21.

MINAYO, M. C. S. \& SOUZA, E. R., 1993. Violência para todos. Cadernos deSaúde Pública, 9:65-78.

NJAINE, K., 1994. Comunicação e Transferência da Informação na Prática Interdisciplinar da Pesquisa: o Centro Latino-Americano de Estudos sobreViolência e Saúde/Claves/ENSP/Fiocruz. Dissertação de Mestrado, Rio de Janeiro: Escola de Comunicação, Universidade Federal do Rio de Janeiro.

PINHEIRO, P. S., 1995. Direitos humanos no ano que passou, avanços e continuidades. In: Os Direitos Humanos no Brasil (Núcleo de Estudos da Violência/Comissão Teotônio Vilela, org.), pp. 5-18. São Paulo: Núcleo de Estudos da Violência/ Comissão Teotônio Vilela.
PITTA, A. M. R., 1995. Interrogando os campos da saúde e da comunicação: notas para o debate. In: Saúde \& Comunicação: Visibilidades e Silêncios (A. M. R. Pitta, org.), pp. 239-266. São Paulo: Hucitec-Abrasco.

REY, G., 1993. Los medios de comunicación y la violencia familiar. Memorias del Seminario Violencia Intrafamiliar, 204:31-45.

RIBEIRO, A. C. T. \& SOUZA, H. S., 1995. Saúde e comunicação: faces contemporâneas da gestão da sociedade. In: Saúde \& Comunicação: Visibilidades e Silêncios (A. M. R. Pitta, org.), pp. 51-66. São Paulo: Hucitec-Abrasco.

RONDELLI, E., 1994/ 95. Mídia, representações sociais da violência, da criminalidade e ações políticas. Comunicação \& Política, 1:97-110.

RONDELLI, E., 1995. Mídia e saúde: os discursos se entrelaçam. In: Saúde \& Comunicação: Visibilidades eSilêncios (A. M. R. Pitta, org.), pp. 38-47. São Paulo: Hucitec-Abrasco.

SODRÉ, M., 1992. O Social Irradiado: Violência Urbana, Neogrotesco e Mídia. Rio de Janeiro: Cortez.

SOUZA, E. R., 1991. Violência Velada e Revelada: Estudo Epidemiológico da Mortalidade por Causas Externas em Duque de Caxias, Rio de Janeiro. Dissertação de Mestrado, Rio de Janeiro: Escola Nacional de Saúde Pública, Fundação Oswaldo Cruz.

SOUZA, E. R., 1994. Homicídios no Brasil: o grande vilão da saúde pública na década de 80 . Cadernos deSaúde Pública, 10 (supl.I):45-60.

SOUZA, E. R. \& FREITAS, M. S., 1995. Do Sonho deVida à Realidade da Morte: Homi cídios de Adolescentes no Rio de Janeiro. Rio de Janeiro: Centro Latino-Americano de Estudos sobre Violência e Saúde “Jorge Carelli”, Escola Nacional de Saúde Pública, Fundação Oswaldo Cruz. (mimeo.)

SOUZA, E. R., ASSIS, S. G. \& SILVA, C. M. F. P., 1996. Violência no Município do Rio de Janeiro: Impacto eTendência da Mortalidade em Adolescentes de 10 a 19 Anos. Rio de Janeiro: Centro Latino-Americano de Estudos sobre Violência e Saúde "Jorge Carelli", Escola Nacional de Saúde Pública, Fundação Oswaldo Cruz. (mimeo.)

TEIXEIRA, M. P., 1994. Raça e crime: orientação para uma leitura crítica do censo penitenciário do Rio de Janeiro. Cadernos do Instituto de Ciências Humanas eFilosofia/ICHF, 64; módulo III, pp. 1-15. 